\title{
Tecle Esc: distopias digitais e saídas tecnoartísticas em Ctrl+Art+Del
}

Rafael Duarte Oliveira Venancio

\section{Resumo:}

Resenha do livro Ctrl+Art+Del: distúrbios em arte e tecnologia.

\section{Palavras Chave:}

Fábio Oliveira Nunes, mídias digitais, web arte.

\section{Abstract:}

Book review Ctrl+Art+Del: distúrbios em arte e tecnologia.

\section{Keywords:}

Fábio Oliveira Nunes, digital media, web art.

NUNES, Fábio Oliveira. Ctrl+Art+Del: distúrbios em arte e tecnologia. São Paulo: Perspectiva, 2010, 314pp.

O medo da vigilância, do domínio totalitário exercido por máquinas, não funda apenas a visão pessimista acerca da tecnologia, mas também algo maior. Algo vai além de um mero temor e que se cristaliza enquanto gênero narrativo marcante do século XX: a distopia.

Negativo da utopia, a distopia possui no medo técnico a sua maior arma mental. Mesmo nos primevos We (1921), de Yevgeny Zamyatin, Admirável Mundo Novo (1932), de Aldous Huxley, e 1984 (1948), de George Orwell, o governo totalitário encontra nas máquinas a sua principal aliada para cumprir o seu protocolo sociopolítico.

Rumando para o fim do século, a distopia, enquanto gênero e enquanto medo social, encontra mais força com o desenvolvimento da reprodutibilidade técnica e com a evolução digital das mídias. Eis o tempo de filmes e de livros novos. É o tempo de William Gibson e o cyberpunk.

Tendo tudo isso em mente, Fábio Oliveira Nunes (Fábio FON), em seu Ctrl+Art+Del: distúrbios em arte e tecnologia, faz um assustador desenho de um começo do século XXI imerso nos controles neotecnológicos: câmeras de vigilância, satélites, celulares, cartões fidelidade, chips de identificação, índices biométricos, sites de relacionamento, Wikipedia, entre outros. No entanto, ao mesmo tempo em que mostra uma digitalidade macabra, Nunes utiliza a outra chave presente nos livros distópicos de Gibson: a possibilidade de saída e de luta via tecnologia.

Para o autor, há uma necessidade pendente de sair dessa ordem homogênea criada pela tecnologia. Tal saída seria pela via tecnoartística, um verdadeiro Ctrl+Alt+Del que representa uma "escolha derradeira e muitas vezes arriscada - em que dados poderão ser perdidos ou avariados. Feitas as escolhas, o sistema 
carregará todas as suas diretrizes novamente e esperaremos que, desta vez, enfim, a ordem seja restabelecida" (NUNES, 2010, p.15).

Assim, para Fábio Oliveira Nunes (2010, p. 19), a ideia principal de seu livro $C t r l+A r t+D e l$ "é a de que caberá aos artistas dos novos meios intervirem especialmente nesse modelo hegemônico, desconstruindo o discurso homogêneo e criando desvios estratégicos". É nesse momento que surge uma produção artística que, ao utilizar dos meios digitais, buscam instaurar distúrbios na ordem hegemônica. O livro inteiro se coloca como um pequeno catálogo de iniciativas e de saídas tecnoartísticas que o autor nos compele a conhecer.

Já na apresentação, feita por Gilbertto Prado, encontramos um chamado à ação:

A reflexão que este livro traz é importante e atual em nossa sociedade midiatizada, na qual diversos setores vêm reenviando suas atenções para as experimentações, transformações e relações com as novas tecnologias de informação e os processos criativos, onde os artistas têm a difícil tarefa de, sem perderem o olhar crítico e sem se desvincularem das circunstâncias de relações em que foram concebidos seus trabalhos, intervirem poeticamente, desconstruindo modelos e criando desvios estratégicos e sensíveis (apud NUNES, 2010, p. 12).

Esses desvios, tal como a introdução de Nunes deixa claro, é o Ctrl+Alt+Del que a arte sempre encarou enquanto missão que agora é enfrentada em campos digitais. Um primeiro exemplo de "Ctrl+Art+Del" é a Freakpedia, a enciclopédia livre dos verbetes de pouca ou nenhuma relevância fundada por Fábio FON e Edgar Franco (www.freakpedia.org). Dessa forma,

a Freakpedia deseja deturpar o modelo de relevância defendido pela conhecida Wikipédia: para os wikipedistas, somente aquilo que for "relevante" deve ser digno de estar presente ali. Com tal concepção, desconsiderando a possibilidade de ir além do paradigma enciclopédico tradicional, os editores reforçam o ideário da mídia de massa e da hegemonia - excluindo tudo aqui que estiver distante do repertório médio de wikipedistas, como produções alternativas e para reduzidos públicos (NUNES, 2010, p. 21).

Após introduzir o livro com a revelação de que até mesmo a Wikipedia é distopicamente tecnomacabra, tendo a necessidade de uma Freakpedia como tentativa de reset, Fábio Oliveira Nunes inicia a sua longa exposição de conceitos, teorias, artes, distopias e saídas ao longo de quatro capítulos.

No primeiro capítulo, intitulado "O Contexto Inserido na Arte", Nunes constrói o solo teórico no qual está embasado sua reflexão. Páginas são dedicadas na reflexão acerca do Dadaísmo e seus objetos de (des)contextualização, a saber: o ready-made, o conceitualismo e a arte postal, além de teorias sucessórias tal como a noção de arte como escultura social (Joseph Beuys), o Situacionismo e a détournement, a Arte Sociológica, e o amplo campo da Estética da Comunicação.

Essa reflexão desemboca na questão da estética relacional e das posturas tecnorrelacionais, que corresponde a um amplo espectro que vai da nossa relação com os despertadores digitais até a questão de um mundo dominado por robôs sociais. É graças à noção de uma arte relacional que há a possibilidade de saídas da distopia digital:

Através dos novos meios, os modelos descritos por Bourriaud podem ganhar uma nova dimensão, não somente simbólica, mas processual. A arte desses meios pode ser capaz de instaurar pequenas interferências com uma complexidade mais intrínseca e precisa; pode também dar origem a novas formas de comportamento, novos gêneros mercantis e novos valores circunscritos num 
microcosmo. Indo em direção ao desvio no interior das relações tecnológicas, despertam-se consciências nas mutações ocorridas no corpo social. É o desafio de realizar uma arte relacional que foca nas relações truncadas, latentes, codificadas e monitoradas agora pelas próprias tecnologias (NUNES, 2010, p. 86).

Já em "Relações e Mediações em Rede", segundo capítulo de Ctrl+Art+Del: distúrbios em arte e tecnologia, Fábio Oliveira Nunes descreve em maiores detalhes o seu principal alvo dentro da distopia digital contemporânea: a Wikipedia. Seu Ctrl+Alt+Del, tal como foi dito, é a Freakpedia que o capítulo se dedica a descrever e traçar um histórico refletido. Em poucas linhas, nas palavras do próprio Nunes (2010, p. 119), a Freakpedia "se mostra como uma enciclopédia que cultua o que nenhuma outra guarda" e nisso reside a força emancipadora dessa web arte.

Emancipadora porque quebraria com a crescente Sociedade dos Figurantes, a atual sucessora da Sociedade do Espetáculo para Nicolas Bourriaud:

A emergência de novas técnicas como a Internet e a multimídia indica um desejo coletivo de criar novos espaços de sociabilidade e de instaurar novos tipos de transações diante do objeto cultural: a "Sociedade do Espetáculo" se sucederia então da sociedade dos figurantes, onde cada um encontraria nos canais de comunicação mais ou menos truncados a ilusão de uma democracia interativa (BOURRIAUD apud NUNES, 2010, p. 152).

Por sua vez, o terceiro capítulo, "Hegemonia Cyborg", representa uma virada. Nunes, mais uma vez, vai para o campo da teoria para refinar a sua conceitualização de uma saída tecnoartística. Páginas, dessa vez, são dedicadas à teoria cyberpunk, à teoria cibernética (Norbert Wiener) e à teoria pós-moderna, retomando nomes como Gilles Deleuze e Paul Virilio.

Dessa reflexão surge na trama textual mais exemplos de saídas tecnoartísticas inspiradas nela. Uma delas, o projeto de web arte Vislumbres Pós-humanos busca relacionar seres híbridos (humanos, monstros, golens) com o amplo domínio do Capital. Esses seres possuem um sistema que gerencia seus comportamentos através do movimento de ações da NASDAQ. Assim, caso uma ação esteja em queda, um determinado ser agirá no contexto dessa instalação web artística de uma determinada forma. Isso tudo busca desvelar que

os aspectos de emergência do contexto contemporâneo - a observação dos padrões que emergem do mercado global - é o que regem a maneira pelo qual o indivíduo, o primeiro elemento dessa cadeia econômica, será recepcionado pelos seres híbridos. É a apropriação dos comportamentos globais para comportamentos pontuais das quimeras aprisionadas no contexto da instalação. Estas, por sua vez, além de personificarem aquilo que a tecnociência vem conquistando rapidamente, apresentam-se como vislumbres de uma nova existência, pós-humana (NUNES, 2010, p. 216).

Por fim, "Tecnologia e seus distúrbios", o quarto capítulo, se dedica a uma ampla descrição de outras iniciativas de web arte. O leitor é colocado diante de um amplo catálogo de saídas tecnoartísticas, um verdadeiro mural de atitudes emancipatórias perante a distopia digital.

Entre essas atitudes, podemos destacar, por exemplo, o Velvet-Strike, de Anne-Marie Schleiner, que é uma versão modificada (MOD) do jogo Counter Strike que permite ao usuário do violento jogo de tiro multiplayer em primeira pessoa - onde equipes de terroristas e de contra-terroristas travam Mexican standoffs digitais - colar adesivo pacifistas (ao invés de atirar) durante uma sessão normal de jogo. Outro bom exemplo é o site Debugging Life, do artista francês JLNDRR, onde o crowdsourcing, ao invés de ser feito para testar algum produto comercial, é focado no grande software, cheio de bugs, chamado vida, ou 
seja, a própria vida em si.

Nas considerações finais, Fábio Oliveira Nunes ressalta, mais uma vez, o papel do mercado e do grande capital na distopia digital. Muito mais do que as próprias técnicas em si, o capital seria o verdadeiro master of puppets nessa distopia. É por isso que pela própria técnica digital seria possível uma saída, representada na conceitualização do livro pela web arte.

Bem inspirada pelo Situacionismo, a obra Ctrl+Art+Del: distúrbios em arte e tecnologia é, em sua própria leitura, um grande escape da ordem vigente. Ao pedir para teclarmos o Ctrl+Alt+Del da web art, o livro se coloca como um grande Esc, permitindo o acesso ao teclado da distopia digital. É o início de uma sequência de escape, rumo ao reboot final.

\section{Bibliografia:}

NUNES, Fábio Oliveira. Ctrl+Art+Del: distúrbios em arte e tecnologia. São Paulo: Perspectiva, 2010, 314pp.

\section{Mini Currículo :}

Rafael Venancio é mestrando em Ciências da Comunicação na Escola de Comunicações e Artes da Universidade de São Paulo (ECA-USP), na área de concentração I: Teoria e Pesquisa em Comunicação e graduado em Comunicação Social - Habilitação em Jornalismo pela ECA-USP. Bolsista de mestrado da Fundação de Amparo à Pesquisa do Estado de São Paulo (Fapesp). Também é autor dos livros Difusão metropolitana e divulgação científica (Plêiade, 2007) e Jornalismo e linha editorial (E-papers, 2009). 